\title{
Water Resource Systems Modeling: Its Role in Planning and Management
}

Planning, designing, and managing water resource systems today inevitably involve impact prediction. Impact prediction can be aided by the use of models. While acknowledging the increasingly important role of modeling in water resource planning and management, we also acknowledge the inherent limitation of models as representations of any real system. Model structure, input data, objectives, and other assumptions related to how the real system functions or will behave under alternative infrastructure designs and management policies or practices may be controversial or uncertain. Future events are always unknown and of course any assumptions about them may affect model outputs, i.e., their predictions. As useful as they may be, the results of any quantitative analysis are always only a part of the information that should be considered by those involved in the overall planning and management decision-making process.

\subsection{Introduction}

Modeling provides a way, perhaps the principal way, of predicting the behavior or performance of proposed system infrastructure designs or management policies. The past 50 years have witnessed major advances in our abilities to model the engineering, economic, ecologic, hydrologic, and sometimes even the institutional or political aspects of large complex multipurpose water resource systems. Applications of models to real systems have improved our understanding of such systems, and hence have often contributed to improved system design, management, and operation. They have also taught us how limited our modeling skills remain.

When design and management decisions are made, they are based on what the decisionmakers assume will take place as a result of their decisions. These predictions are based on qualitative information and beliefs in peoples' heads, as illustrated in Fig. 2.1, possibly informed by quantitative information provided by mathematical or computer-based models as illustrated in Fig. 2.2. Computer-based modeling is used to enhance mental models. These quantitative mathematical models are often considered essential for carrying out environmental impact assessments. Mathematical simulation and optimization models packaged within interactive computer programs provide a common way for planners and managers to predict the behavior of any proposed water resources system design or management policy before it is implemented.

Water resource systems are typically far more complex than what analysts can model and simulate. The reason is not primarily due to computational limitations but rather it is because we do not understand sufficiently the multiple interdependent physical, biochemical, ecological, social, legal, and political (human) processes that govern the behavior of such water resource systems. People and their institutions impact the performance of such systems, and the 


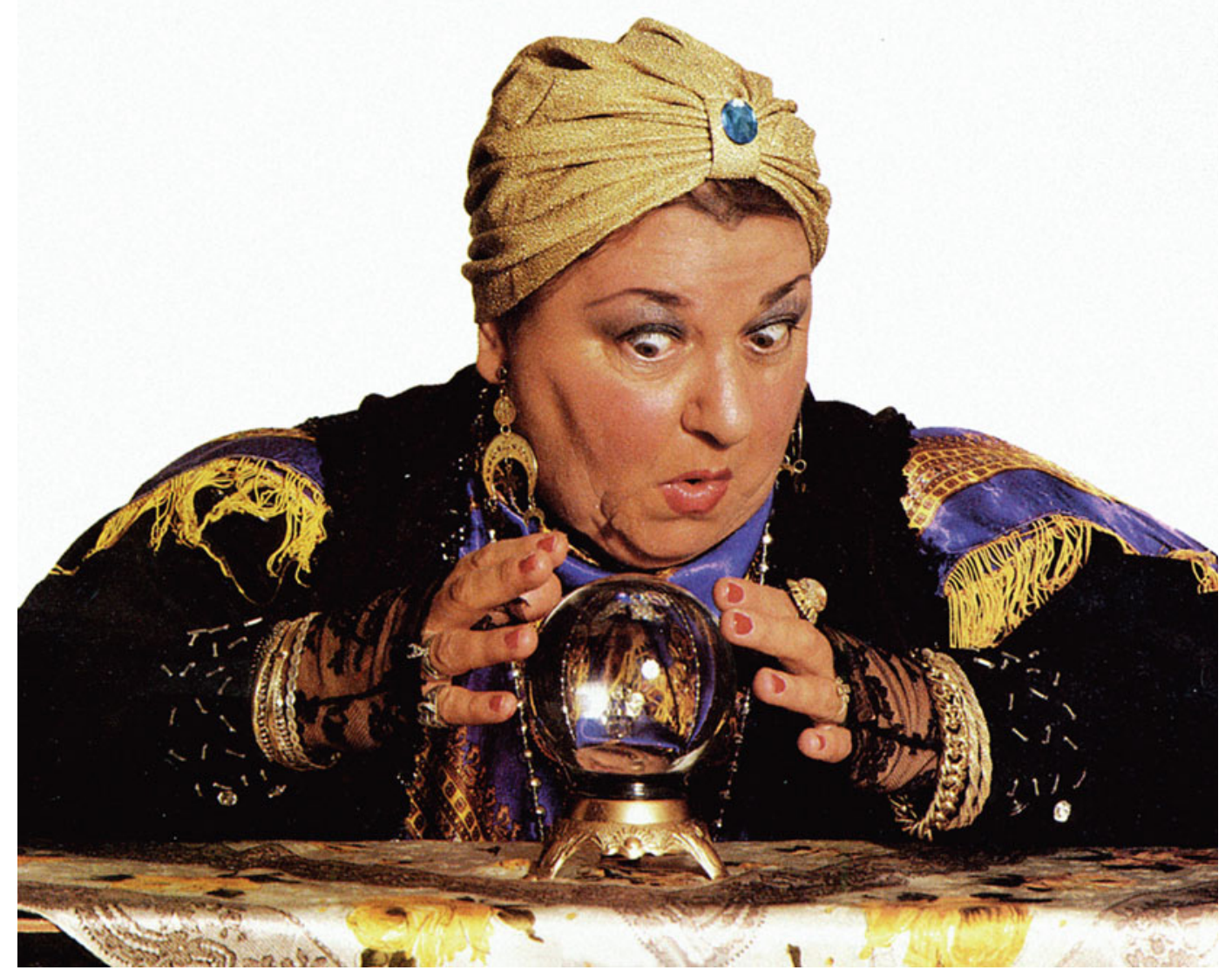

Fig. 2.1 Using mental models for prediction

performance of these systems impacts people. System performance is affected by uncertainties in things we can measure and processes we can predict. They are also affected by the unpredictable actions of individuals and institutions as they manage and use water in response to a multitude of impacts they experience in their physical and social environment. Some of these impacts are water related. Others have nothing directly to do with water.

The development and application of models, i.e., the art, science, and practice of modeling, as will be discussed in the following chapters, should be preceded by a recognition of what can and cannot be achieved from the use of models. Models of real-world systems are always simplified representations of those systems. What features of the actual system are represented in a model, and what features are not, will depend in part on what the modeler thinks is important with respect to the issues being discussed or the questions being asked. How well this is done will depend on the skill of the modeler, the time and money available, and, perhaps most importantly, the modeler's understanding of the real system and decision-making process.

Developing models is an art. It requires knowledge of the system being modeled, the client's objectives, goals, and information needs, and some analytical and programming skills. Models are always based on numerous assumptions or approximations, and some of these may be at issue. Applying these approximations of reality in ways that improve understandings and eventually lead to a good decision clearly requires not only modeling skills but also the 
ability to communicate and effectively work with stakeholders and decision-makers.

Models produce information. They do not make decisions or replace those individuals that do. But they can inform them. Water resource planners and managers must accept the fact that decisions may not be influenced by the results of their planning and management models. If model results are not available when needed, they are likely to be ignored when they become available. If model results do not support the preferences of decision-makers, they may also not be considered. To know, for example, that cloud seeding may, on average, reduce the strength of hurricanes over a large region does not mean that such cloud-seeding activities will or should be undertaken. And it is unlikely everyone, even so-called experts, will agree on any recommended course of action. Managers or operators may know that not everyone may benefit from what they would like to do, and those who lose will likely scream louder than those who gain.

In addition, decision-makers may feel safer in inaction than action (Shapiro 1990; Simon 1998). There is a strong feeling in many cultures and legal systems that fail to act (nonfeasance) is considered more acceptable than acts that fail (misfeasance or malfeasance). We all feel greater responsibility for what we do than for what we do not do. Yet our aversion to risks of failure should not deter us from addressing sensitive planning or policy issues in our models. Modeling efforts should be driven by the need for information and improved understanding. It is that improved understanding (not improved models per se) that may eventually lead to improved system design, management, and/or operation. Models used to aid water resource planners and managers are not intended to be, and rarely are (if ever), a replacement of their judgment. This we have learned, if nothing else, in our over 50 years of modeling experience.

This brief chapter serves to introduce this art of modeling and its applications. The emphasis throughout this book is on application. This chapter is about modeling in practice more than in theory. It is based on the considerable experience and literature pertaining to how well, or how poorly, professional practitioners and researchers have done over the past five decades or more in applying various modeling approaches or tools to real problems with real clients (also see, for example, Austin 1986; Brown et al. 2015; Cai et al. 2013; Castelletti and Soncini-Sessa 2007; Gass 1990; Kindler 1987, 1988; Loucks et al. 1985; Reynolds 1987; Rogers and Fiering 1986; Russell and Baumann 2009; Watkins 2013).

In attempting to understand how modeling can better support planners and managers, it may be useful to examine just what planners and managers of complex water resource systems do. What planners or managers do governs to some extent what they need to know. And what they need to know governs to a large extent what modelers or analysts should be trying to provide. In this book the terms analysts or modelers, planners, and managers can be the same person or group of individuals. These terms are used to distinguish the activities of individuals, not necessarily the individuals themselves.

First, we offer some general thoughts on the major challenges facing water resource systems planners and managers, the information they need to meet these challenges, and the role analysts have in helping to provide this information. Next, we review some criteria for evaluating the success of any modeling activity designed to help planners or managers solve real problems. Finally, we argue why we think the practice of modeling is in a continual state of transition, and how current research and development in modeling as well as improvements in computing technology are affecting that transition.

\subsection{Modeling Water Resource Systems}

As will be discussed in greater detail in the following chapters of this book, there are many types of models and modeling approaches that have been developed and used to identify, study, and evaluate alternative water resource designs, management plans, and operating policies. But before outlining these model types and modeling approaches and how they can be used to best 
Fig. 2.2 Using computer-based mathematical models for prediction

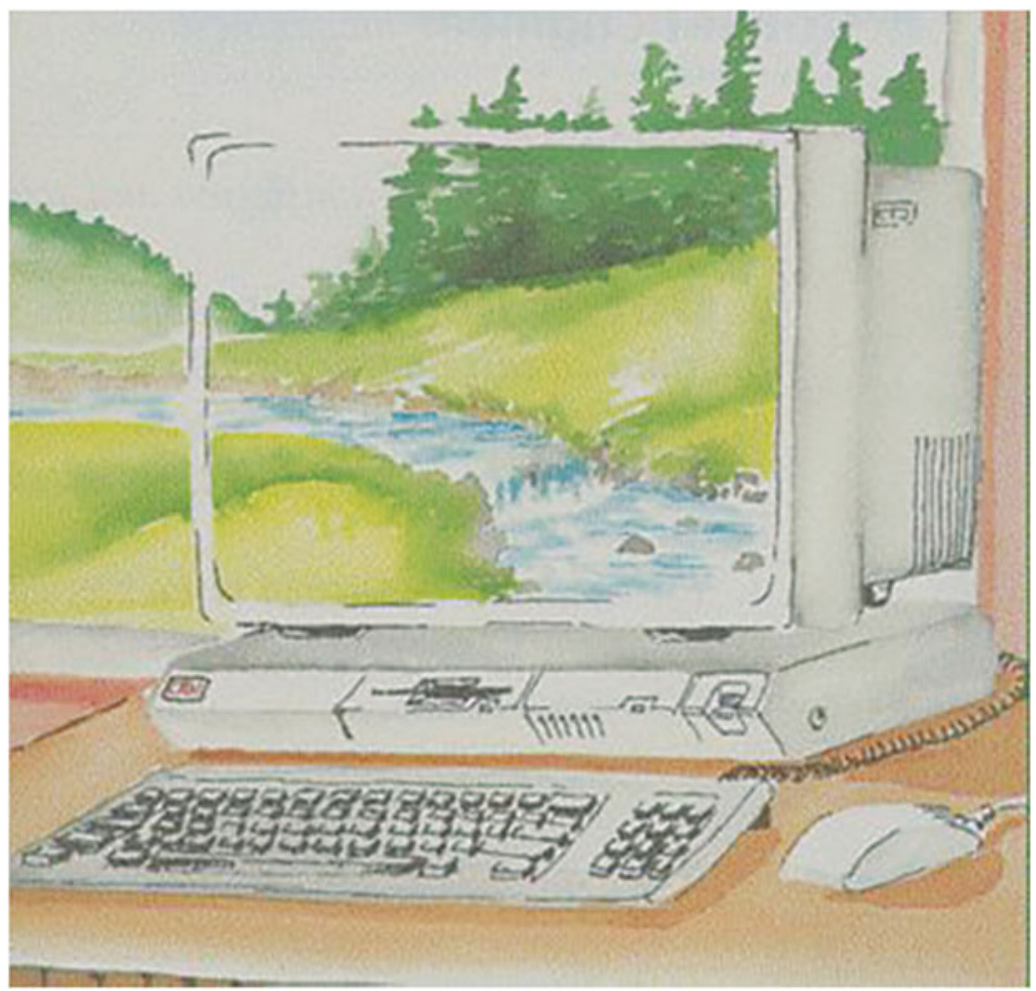

meet the needs of planners and managers, it may be useful to describe a specific modeling example based on Borsuk et al. (2001). In this example, a sequence of models are used to assess how effective reductions in upstream nutrient runoff may be in improving the habitat for fish and shellfish in a downstream estuary.

This example is followed by a discussion of the conditions needed that motivate the use of models, whether solely mental (Fig. 2.1) or both mental and mathematical (Fig. 2.2).

\subsubsection{An Example Modeling Approach}

Consider for example the sequence or chain of models illustrated in Fig. 2.3 required for the prediction of fish and shellfish survival as a function of nutrient loadings into an estuary. The condition of the fish and shellfish are important to the economy of the region and the income of many stakeholders. One way to maintain healthy stocks is to maintain sufficient levels of oxygen in the estuary. The way to do this is to control algae blooms. This in turn requires limiting the nutrient loadings to the estuary that can cause algae blooms and subsequent dissolved oxygen deficits. The modeling challenge is to link nutrient loading to fish and shellfish survival. In other words, can some quantitative relationship be defined relating the amount of nutrient loading to the amount of fish and shellfish survival?

The negative effects of excessive nutrients (e.g., nitrogen) in an estuary are shown in Fig. 2.3. Nutrients stimulate the growth of algae. Algae die and accumulate on the bottom where bacteria consume them. Under calm wind conditions density stratification occurs. Oxygen is depleted in the bottom water. As a consequence, fish and shellfish may die or become weakened and more vulnerable to disease.

A sequence of models, each providing input data to the next model, can be defined to predict shellfish and fish abundance in the estuary based on upstream nutrient loadings. These models, for 


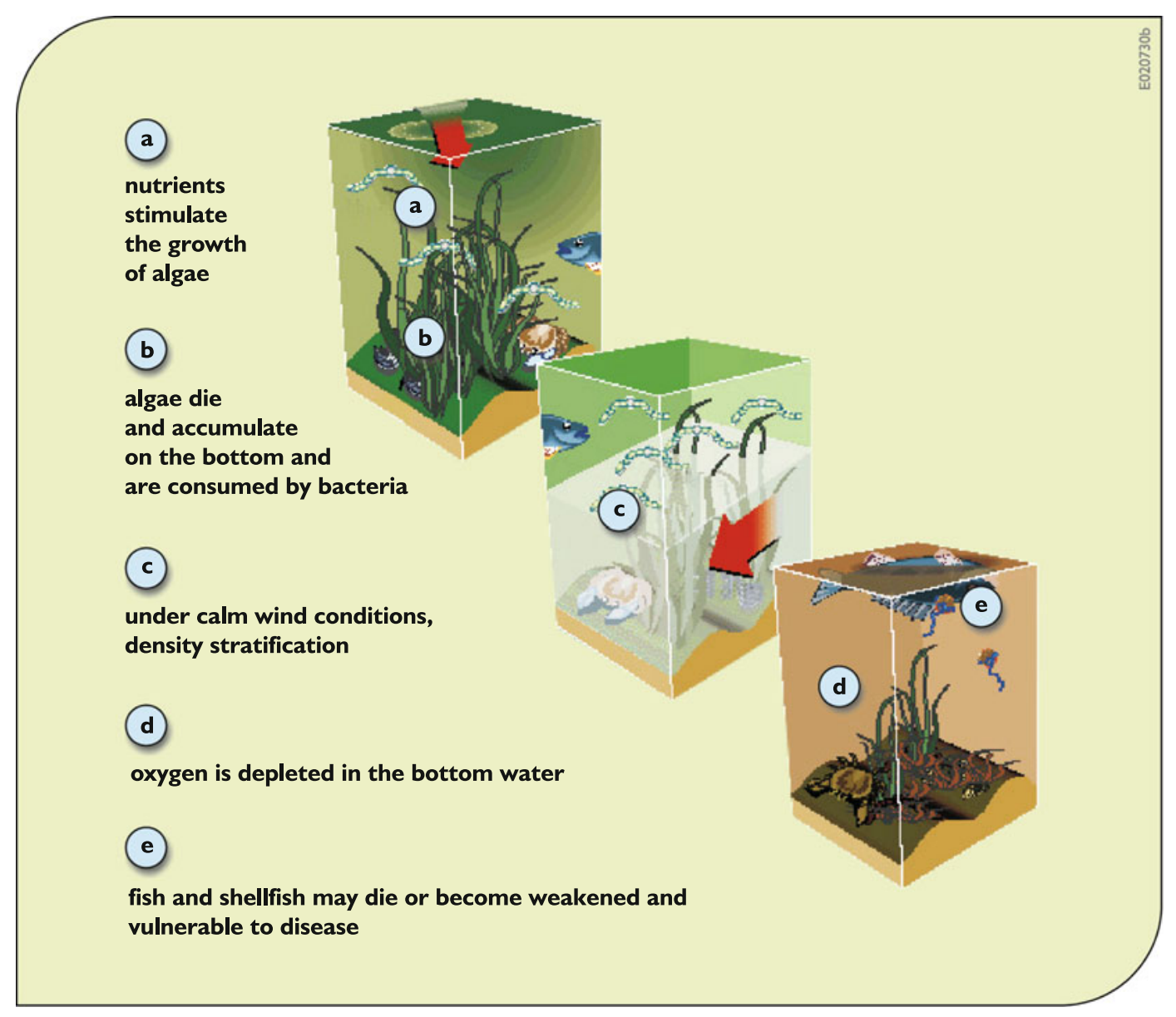

Fig. 2.3 The impacts of excessive nutrients in an estuary

each link shown in Fig. 2.4, can be a mix of judgmental, mechanistic, and/or statistical ones. Statistical models could range from simple regressions to complex artificial neural networks. Any type of model selected will have its advantages and its limitations. Its appropriateness may largely depend on the amount and precision of the data available for model calibration and verification.

The results of any modeling exercise should be expressed in terms meaningful and of interest to those that will be making decisions taking into account those results. In this example 'shell-fish abundance' and 'number of fish-kills' are meaningful indicators to stakeholders and can be related to designated water body use.

\subsubsection{Characteristics of Problems to be Modeled}

Problems motivating modeling and analyses exhibit a number of common characteristics. These are reviewed here because they provide insight into whether a modeling study of a particular problem may be worthwhile. If the planners' objectives are very unclear, if few alternative courses of action exist, or if there is little scientific understanding of the issues involved, then mathematical modeling and other more sophisticated methodologies are likely to be of little use.

Successful applications of modeling are often characterized by: 


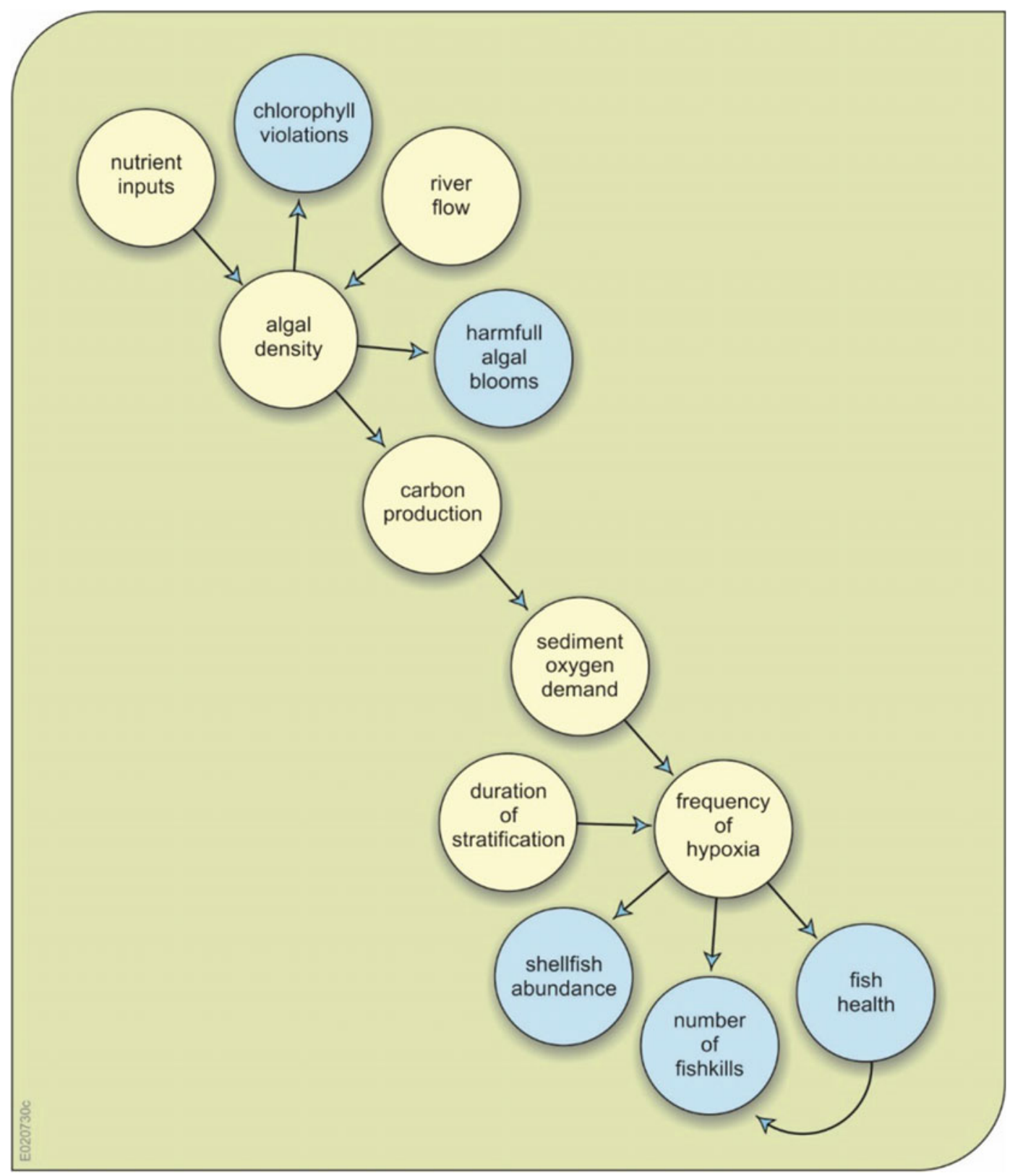

Fig. 2.4 Cause and effect diagram for estuary eutrophication due to excessive nutrient loadings (after Borsuk et al. 2001)

- A systems focus or orientation. In such situations attention needs to be devoted to the interdependencies and interactions of elements or components within the system as a whole, as well as to the elements or components themselves.
- The use of interdisciplinary teams. In many complex and nontraditional problems, it is not at all clear from the start what mix of disciplinary viewpoints will turn out to be most appropriate or acceptable. It is essential that participants in such work-coming from 
different established disciplines-become familiar with the techniques, vocabulary, and concepts of the other disciplines involved. Participation in interdisciplinary modeling often requires a willingness to make mistakes at the fringes of one's technical competence and to accept less than the latest advances in one's own discipline.

- The use offormal mathematics. Most analysts prefer to use mathematical models to assist in system description and the identification and evaluation of efficient tradeoffs among conflicting objectives, and to provide an unambiguous record of the assumptions and data used in the analysis.

Not all water resources planning and management problems are suitable candidates for study using modeling methods. Modeling is most likely to be appropriate when:

- The planning and management objectives are reasonably well defined, and organizations and individuals can be identified who can benefit from obtaining and understanding the model results.

- There are many alternative decisions that may satisfy the stated objectives, and the best decision is not obvious.

- The water resources system and the objectives being analyzed are describable by reasonably tractable mathematical representations.

- The information needed, such as the hydrological, economic, environmental, and ecological impacts resulting from any decision, can be better estimated through the use of models.

- The values of the model parameters are estimable from readily obtainable data.

\subsection{Challenges Involving Modeling}

Modeling activities present challenges to those who do it as well as those who sponsor it and may potentially benefit from model results.

\subsubsection{Challenges of Planners and Managers}

Planners and managers of water resource systems are responsible for solving particular water-related problems or meeting special water resource needs. When they fail, they hear about it. The public lets them know. (Example: the lead contamination in the drinking water of Flint, Michigan USA, after a switch in the water source to reduce costs.) What makes their job particularly challenging is that stakeholders often have different needs and expectations. Furthermore, institutions where water resource planners and managers work (or hire consultants to work for them) are like most institutions these days. They must do what they have been asked to do with limited financial and human resources. Their clients include all of us who use water, or at least all of us who are impacted by the decisions they make.

The overall objective of planners, managers, and operators and their institutions is to provide a service, such as reliable and inexpensive supplies of water, assurance of water quality, production of hydropower, protection from floods, provision of commercial navigation and recreational opportunities, preservation of wildlife and enhancement of ecosystems, or some combination of these or other purposes. Furthermore they are expected to do this at a cost no greater than what people are willing to pay. Meeting these goals, i.e., keeping everyone happy, is not always easy, or even possible.

Simple technical measures or procedures are rarely available that will ensure a successful solution to any particular set of water resource management problems. Furthermore, everyone who has had any exposure to water resources planning and management knows one cannot design or operate a water resource system without making compromises. These compromises often involve competing purposes (such as hydropower and flood control) or competing objectives (such as who benefits and who pays, and how much and where and when). After analysts, using their models of course, identify 
possible ways of achieving various goals and objectives and provide estimates of associated economical, environmental, ecological, and social impacts, it is the decision-makers who have the more difficult job. They must work with and influence everyone who will be affected by any decision.

Planning and managing involves not only decision-making, but also developing among all interested and influential individuals an understanding and consensus that legitimizes the decisions and enhances their successful implementation. Planning and managing are processes that take place in a social or political environment. These processes involve leadership and communication among people and institutions. Leadership and communication skills are learned from experience working with people, not sitting alone working with computers or models.

Moving an organization or institution into action to achieve specific goals involves a number of activities, including goal-setting, debating, coordinating, motivating, deciding, implementing, and monitoring. Many of these must be done simultaneously and continuously, especially as conditions (goals and objectives, water supplies, water demands, financial budgets) change over time. These activities create a number of challenges that are relevant to modelers or analysts. Some include:

1. identifying creative ways of solving problems.

2. finding out what each interest group wants to know in order to reach an understanding of the issues and a consensus on what to do.

3. developing and using models and presenting their results so that everyone can reach a common or shared understanding and agreement that is consistent with their individual values.

4. making decisions and implementing them given differences in opinions, social values, and objectives.

In addressing these needs or challenges, planners, and managers must consider the relevant
- legal rules and regulations;

- history of previous decisions;

- preferences of important actors and interest groups;

- probable reactions of those affected by any decision;

- relative importance of various issues being addressed; and finally;

- sciences, engineering, and economics - the technical aspects of their work.

We mention these technical aspects last not to suggest that they are the least important factor to be considered. We do this to emphasize that they are only among many factors and, probably in the eyes of planners and managers, not the most decisive or influential (Ahearne 1988; Carey 1988; Pool 1990; Thissen and Walker 2013; Walker 1987).

So, does the scientific, technical, systematic approach to modeling for planning and management really matter? We believe it can if it addresses the issues of concern to their clients, the planners, and managers. Analysts need to be prepared to interact with the political or social structure of the institutions they are attempting to assist, as well as with the public and the press. Analysts should also be prepared to have their work ignored. Even if analysts are presenting 'facts' based on the current state of the sciences, sometimes these sciences are not considered relevant. Happily for scientists and engineers, this is not always the case. The challenge of modelers or analysts interested in having an impact on the performance of water resource systems is to become a part of the largely political planning and management process and to contribute towards its improvement.

\subsubsection{Challenges of Modelers}

To engage in a successful water resource systems study, the modeler must possess not only the requisite mathematical and systems modeling skills, but also an understanding of the environmental engineering, economic, political, cultural, 
and social aspects of water resources planning problems. Consider, for example, the study of a large land development plan. The planner should be able to predict how the proposed development would affect the quantity and quality of the surface and subsurface runoff and how this will impact the quantity and quality of surface waters and ground waters and their ecosystems. These impacts, in turn, might affect the planned development itself, or others downstream. To do this the analysts must have an understanding of the biological, chemical, and physical and even social processes that are involved in water resources management.

A reasonable knowledge of economic theory, law, regional planning, and political science can be just as important as an understanding of hydraulic, hydrogeologic, hydrologic, ecologic, and environmental engineering disciplines. It is obvious that the results of most water resources management decisions have a direct impact on people and their relationships. Hence, inputs from those having knowledge of these disciplines are useful during the comprehensive planning of water resource systems.

Some of the early water resource systems studies were often undertaken with a naive view of the appropriate role and impact of models and modelers in the policymaking process. Policymakers could foresee the need to make a decision. They would ask the systems group to study the problem. These analysts would then model the problem, identify feasible solutions and their consequences, and recommend one or at most a few alternative solutions. The policymakers, after waiting patiently for these recommendations, would then make a yes or no decision. Experience to date suggests the following:

1. A final solution to a water resources planning problem rarely exists; plans and policies are dynamic. They evolve over time as facilities are added and modified to adapt to changes in management objectives and in the demands placed on the facilities.

2. For every major decision there are many minor decisions, made by different agencies or management organizations responsible for different aspects of a system.
3. The times normally available to study particular water resources problems are shorter than the times needed to do a thorough study, or if there is sufficient time, the objectives of the original study will likely have significantly shifted by the time the study is completed.

This experience emphasizes some of the limitations and difficulties that any water resource systems study may encounter, but more importantly, it underscores the need for constant communication among the analysts, system planners, managers and operators, and policymakers. The success or failure of many past water resource studies is due largely to the efforts expended or not expended in ensuring adequate, timely and meaningful communication-communication among systems analysts, planners, those responsible for system operation and design, and public officials responsible for major decisions and setting general policies. Decision-makers, who can benefit from the information that can be derived from various models and analyses, need it at particular times and in a form useful and meaningful to them. Once their window of opportunity for decision-making has passed, such information, no matter how well presented, is often useless.

At the beginning of any study, objectives are usually poorly defined. As more is learned about what can be achieved, stakeholders are better able to identify what they want to achieve. Close communication among analysts and all interested stakeholders and decision-makers throughout the modeling process is essential if systems studies are to make their greatest contribution to the planning process. Objectives as stated at the beginning of a study often differ from the objectives as understood at the end of a study.

Furthermore, it is helpful if those who will use models, and present the information derived from models to those responsible for making decisions, are intimately involved with model development, solution, and analysis. Only then can they appreciate the assumptions upon which any particular model output is based, and hence adequately evaluate the reliability of the results. 
Any water resource systems study that involves only outside consultants, and minimal communication between consultants and planners within a responsible management agency or involved stakeholders, is not likely to have a significant impact on the planning process. Models that are useful tend to be those that are constantly being modified and applied by those involved in plan preparation, evaluation, and implementation.

\subsubsection{Challenges of Applying Models in Practice}

The clients of modelers or analysts are typically those who have problems to solve and who could benefit from a better understanding of what options they have and what impacts may result. They want advice on what to do and why, what will happen given what they do, and who will care and how much. The aim of analysts is to provide them with meaningful (understandable), useful, accurate, and timely information. This information is to help them better understand their system, its problems, and alternative ways to address them. In short, the purpose of water resource systems planning and management modeling is to provide useful and timely information to those involved in managing such systems.

Modeling is a process or procedure intended to focus and force clearer thinking and to promote better decision-making. The approach involves problem recognition, system definition, and bounding; identification of various goals or objectives; identification and evaluation of various alternatives; and very importantly, effective communication of this information to those who can benefit from it.

The focus of most books and articles on water resource systems modeling is on modeling methods. This book is no different. But what all of us should also be interested in, and discuss more than we do, is the use of these tools in the processes of planning and management. If we did, we could learn much from each other about what tools are needed and how they can be better applied in practice. We could extend the thoughts of those who, in a more general way, addressed these issues over four decades ago (Majoni and Quade 1980; Tomlison 1980; Miser 1980; Stokey and Zeckhauser 1977).

There is always a gap between what researchers in water resource systems modeling produce and publish, and what the practitioner finds useful and uses. Those involved in research are naturally interested in developing new and improved tools and methods for studying, identifying, and evaluating alternative water resource system designs and management and operation policies. If there were no gap between what is being developed or advocated by researchers and that which is actually used by practitioners, either the research community would be very ineffective in developing new technology or the practitioners would be incredibly skilled in reading, assimilating, evaluating, and adapting what is worth adapting from this research to meet their needs. Evaluation, testing, and inevitable modifications take time. Not all published research is ready or suited for implementation. By definition research is a work in progress.

How can modelers help reduce the time it takes for new ideas and approaches to be adopted and used in practice? Clearly, practitioners are not likely to accept a new modeling approach or even modeling itself unless it is obvious that it will improve the performance of their work as well as help them address problems they are trying to solve. Will some new model or computer program make it easier for practitioners to carry out their responsibilities? If it will, there is a good chance that the model or computer program might be successfully used, eventually. Successful use of the information derived from models or programs is, after all, the ultimate test of the value of those models or programs. Peer review and publication is only one, and perhaps not even a necessary, step towards that ultimate test or measure of value of a particular model or modeling approach. 


\subsubsection{Evaluating Modeling Success}

There are a number of ways one can judge success (or failure) in applying models in practice. Goeller (1988) suggested three measures as a basis for judging success:

1. How the analysis was performed and presented (analysis success);

2. How it was used or implemented in the planning and management processes (application success); and

3. How the information derived from the model and its application affected the system design or operation and the lives of those who used the system (outcome success).

The extent to which the models and methods and style of presentation are appropriate for the problem being addressed, the resources and time available for the study, and the institutional environment of the client, are often hard to judge. Publishing in peer-review journals and review panels are two ways of judging. No model or method is without its limitations. Two other obvious indications are the feeling analysts have about their own work and, very importantly, the feeling the clients have about the analysts' work. Client satisfaction may not be an appropriate indicator if, for example, they are unhappy only because they are learning something they do not want to accept. Producing results primarily to reinforce a client's prior position or opinions might result in client satisfaction but, most would agree, this is not an appropriate goal of modeling.

Application or implementation success implies that the methods and/or results developed in the study were seriously considered by those involved in the planning and management process. One should not, it seems to us, judge success or failure based on whether or not any of the model results, i.e., the computer 'printout,' were directly implemented. What one hopes for is that the information and understanding resulting from model application helped define and focus the problem and possible solutions, and helped influence the debate among stakeholders and decision-makers about what decisions to make or actions to take. The extent to which this occurs is the extent to which a modeling study will have achieved application or implementation success.

Outcome success is based on what happened to the problem situation once a decision (that was largely influenced by the results of modeling) was made and implemented. The extent to which the information and understanding resulting from modeling helped solve the problems or resolve the issues, if it can be determined, is a measure of the extent of outcome success.

It is clear that success based on any of the last two of the three criteria will be strongly dependent on the success of the preceding criteria. Modeling applications may be judged successful based on the first two measures, but perhaps because of unpredicted events, the problems being addressed have become worse rather than improved, or while those particular problems were eliminated, their elimination caused one or more even more severe problems. All of us can think of examples where this has happened. The previously mentioned lead contamination in the drinking water of Flint, Michigan, resulting from trying to reduce costs is one example. Any river restoration project involving the removal of engineering infrastructure is another example of changing objectives or new knowledge following previous decisions that no longer work very well. Who knows - a broader systems study might have helped planners, managers, and decisionmakers foresee such consequences, but one cannot count on that. Hindsight is always clearer than foresight. Much of what takes place in the world is completely unpredictable. Given this, it is not clear whether we should hold modelers or analysts, or even planners or managers, completely responsible for any lack of 'outcome success' if unforeseen events change society's goals, priorities, and understanding.

Problem situations and criteria for judging the extent of success are likely to change over time. By the time one can evaluate outcome success, the system itself may have changed enough for the outcome to be quite different than what was predicted in the analysis. Monitoring the performance of any decision, whether or not based on a successfully analyzed and implemented 
modeling effort, is often neglected. But monitoring is very important if changes in system design, management, and operation are to be made to adapt to changing and unforeseen conditions.

If the models, data, computer programs, documentation, and know-how are successfully maintained, updated, and transferred to and used by the client institutions, there is a good chance that this methodology will be able to provide useful information relevant to the changes that are needed in system design, management, or operation. Until relatively recently, the successful transfer of models and their supporting technology have involved a considerable commitment of time and money for both the analysts as well as the potential users of the tools and techniques. It has been a slow process. Developments in interactive computer-based decision support systems that provide a more easily understood humanmodel-data-computer interface have substantially facilitated this technology transfer process. These interactive interface developments have had a major impact on the state of the practice in using models in the processes of water resources planning and management.

\subsection{Developments in Modeling}

\subsubsection{Technology}

The increasing developments in computer technology - from mobile devices to microcomputers and workstations to supercomputers - and all their software applications - have motivated the concurrent development of an impressive set of new models and accompanying software. This software is aimed at facilitating model use and, more importantly, interaction and communication between the analysts or modelers and their clients. This new software includes

1. Interactive approaches to model operation that put users more in control of their computers, models, and data;

2. Computer graphics that facilitate data input, editing, display, and comprehension;
3. Geographic information systems that provide improved spatial analysis and display capabilities;

4. Expert systems that can help the user understand better how complex decision problems might be solved and at the same time explain to the users why one particular decision may be better than another;

5. Cloud computing, electronic mail, and the Internet that lets analysts, planners, and managers communicate and share data and information with others worldwide, and to run models that are located and maintained at distant sites;

6. Multimedia systems that permit the use of sound and video animation in analyses, all aimed at improved communication and understanding.

These and other software developments are giving planners and managers improved opportunities for increasing their understanding of their water resource systems. Such developments in technology should continue to aid all of us in converting model output data to information, i.e., it should provide us with a clearer knowledge and understanding of the alternatives, issues, and impacts associated with potential solutions to water resource systems problems. But once again, this improved information and understanding will only be a part of what planners and managers must consider.

Will all the potential benefits of new technology actually occur? Will analysts be able to develop and apply these continual improvements in new technology wisely? Will we avoid another case of oversell or unfulfilled promises? Will we avoid the temptation of generating fancy animated, full-color computer displays just because we are easily able to, rather than being motivated by the hope that such methods will add to improved understanding of how to solve problems more effectively? Will we provide the safeguards needed to ensure the proper use and interpretation of the information derived from increasingly user-friendly computer programs? Will we keep a problem-solving focus, and continue to work towards increasing our understanding of how to 
improve the development and management of our water resources whether or not our planning models are incorporated into some sort of interactive computer-aided support system? We can, but it will take discipline.

As modelers or researchers, we must discipline ourselves to work more closely with our clientsthe planners, managers, and other specialists who are responsible for the development and operation of our water resource systems. We must study their systems and their problems, and we must identify their information needs. We must develop better tools that they themselves can use to model their water resource systems and obtain an improved understanding - a shared vision — of how their system functions and of their available management options and associated impacts or consequences. We must be willing to be multidisciplinary and capable of including all relevant data in our analyses. We must appreciate and see the perspectives of the agronomists, ecologists, economists, engineers, hydrologists, lawyers, or political and regional scientists - you name it - as appropriate. Viewing a water resource system from a single-discipline perspective is rarely sufficient to meet today's water resource systems planning challenges.

Even if we have successfully incorporated all relevant disciplines and data in our analyses, we should have a healthy skepticism about our resulting information. We must admit that this information, especially concerning what might happen in the future, is uncertain. If we are looking into the future (whether using crystal balls or mathematical models), we must admit that many of our assumptions, e.g., parameter values, cannot even be calibrated let alone verified. Our conclusions or estimates can be very sensitive to our assumptions. One of our major challenges is to communicate this uncertainty in understandable ways to those who ask for our predictions.

\subsubsection{Algorithms}

Accompanying the improvements in the technology of computing that has had an enormous impact on the capability of analysts to address and study increasingly complex issues in water resource systems planning and management, improvements made in the mathematical and computational algorithms have permitted the modeling of more complex systems problems. All our algorithms that have been applied to the analysis of water resource systems, have their strengths and limitations. We still lack the 'perfect' all-purpose algorithm. And it is not likely that we will find one in the future. Probably the major determinant of a particular algorithm or software package chosen to address a particular problem or development opportunity is that which the analyst is most familiar with and experienced in using.

Nevertheless, the menu of available algorithms that can be used for analyses is considerably larger today than what it was when the seminal book on the design of water resource systems (Maas et al. 1962) was published over six decades ago. At that time mathematical programming (constrained optimization) software applied to mainly deterministic linear and nonlinear problems dominated the interests of those working toward improved models for preliminary screening of water resource systems prior to more detailed simulation modeling. Simulations were based on software and constrained by the internal and magnetic tape memory capacity of computers available at that time. Today our focus is more on methods suited for enhancing stakeholder participation. Much of it based on the results of research in artificial intelligence, examples including evolutionary search methods based on biological processes, multi-agent modeling, artificial neural networks, and data mining methods.

\subsubsection{Interactive Model-Building Environments}

Water resources planners and managers today must consider the interests and goals of numerous stakeholders. The planning, managing, and decision-making processes involve negotiation and compromise among these numerous stakeholders, such as those shown in Fig. 2.5, who 
Fig. 2.5 Stakeholders involved in river basin planning and management, each having different goals and information needs

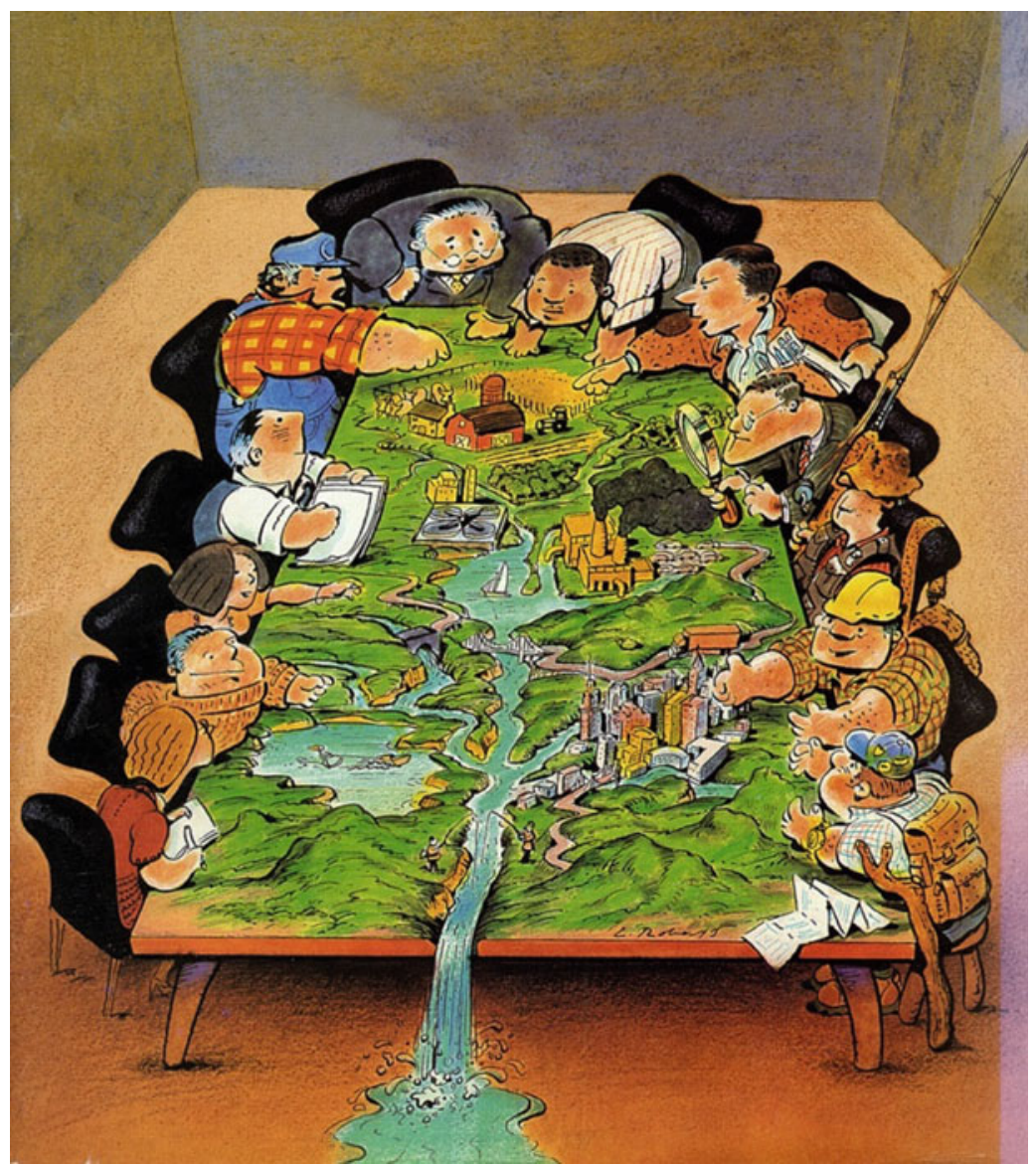

typically have different interests, objectives and opinions about how their water resource system should be managed. How do we model to meet the information needs of all these different stakeholders? How can we get them to believe in and accept these models and their results? How do we help them reach a common-shared-vision? How can we help create a shared vision among all stakeholders of at least how their system works and functions, if not how they would like it to?

Today we know how to build some rather impressive models of environmental systems. We know how to incorporate within our models the essential biology, chemistry and physics that govern how the environmental system works. We have also learned a little about how to include the relevant economics, ecology, and engineering into these models. Why do we do this? We do all this modeling simply to be able to estimate, or identify, and compare and evaluate the multiple impacts resulting from different design and management decisions we might make. Such information, we assume, should be of value to those responsible for choosing the 'best' decision.

If our goal is to help contribute to the solution of, water resources problems, simply having information from the world's best models and technology, as judged by our peers, is not a guarantee of success. To be useful in the political decision-making process, the information we analysts generate with all our models and computer technology must be understandable, credible, and timely. It must be just what is needed when it is needed. It must be not too little and not too much.

The optimal format and level of detail and precision of any information generated from 
models should depend on the needs and backgrounds of each individual involved in the decision-making process. The value of such information, even if the format and content are optimal, will also depend on when it is available. Information on an issue is only of value if it is available during the time when the issue is being considered-i.e., when there is an interest in that issue and a decision concerning what to do about it has not yet been made. That is the window of opportunity when information can have an impact. Information is of no value after the decision is made unless of course that information results in opening up another window of opportunity.

If there is truth in the expression "decision makers don't know what they want until they know what they can get," how do modelers know what decision-makers will need before even they do? How will modelers know what is the right amount and detail of information? How will they know especially if they are to have that information available, and in the proper form, before or at, the time it is needed? Obviously modelers cannot know this. However, over the past three decades or so this challenge has been addressed by developing and implementing decision support systems (DSSs) (Fedra 1992; Georgakakos and Martin 1996; Loucks and da Costa 1991). These interactive modeling and display technologies can, within limits, adapt to the level of information needed and can give decision-makers some control over data input, model operation, and data output. But will each decision-maker, each stakeholder, trust the model output? How can they develop any confidence in the models contained in a DSS? How can they modify those models within a DSS to address issues the DSS developer may not have considered? An answer to these questions has been the idea of involving the decision-makers themselves not only in interactive model use, but in interactive model building as well. This approach is commonly termed collaborative modeling.

Figure 2.6 gives a general view of the components of many decision support systems. The essential feature is the interactive interface that permits easy and meaningful data entry and display, and control of model (or computer) operations. Depending on the particular issue at hand, and more importantly the particular individuals and institutions involved, a decision support system in the broadest sense can range from minimal if any computer model usewhere the decision-makers provide all the data and analyses, make the decision, and they or their institutions implement those decisions - to decision support systems that are fully automated and where no human involvement is present. The latter are rare, but they do exist. The automatic closing of the flood gates when there is a high risk of flooding in Rotterdam harbor is an example of this.

Involving stakeholders in model building gives them a feeling of ownership. They will have a much better understanding of just what their model can do and what it cannot do. If they are involved in model building, they will know the assumptions built into their model. Being involved in a joint modeling exercise is a way to understand better the impacts of various assumptions. While there may be no agreement on the best of various assumptions to make, stakeholders can learn which of those assumptions matter and which do not. In addition, just the process of model development by numerous stakeholders will create discussions that can lead toward a better understanding of everyone's interests and concerns. Though such model-building exercises, it is just possible those involved will gain not only a better understanding of everyone's concerns, but also a common or 'shared' vision of at least how their water resource system (as represented by their model, of course) works. Experience in stakeholder involvement in model building suggests such model-building exercises can also help multiple stakeholders reach a consensus on how their real system should be developed and managed.

In the US, one of the major advocates of shared vision or collaborative modeling is the Institute for Water Resources of the US Army Corps of Engineers. They have applied their interactive general-purpose model-building platform in a number of exercises where conflicts existed over the design and operation of water 


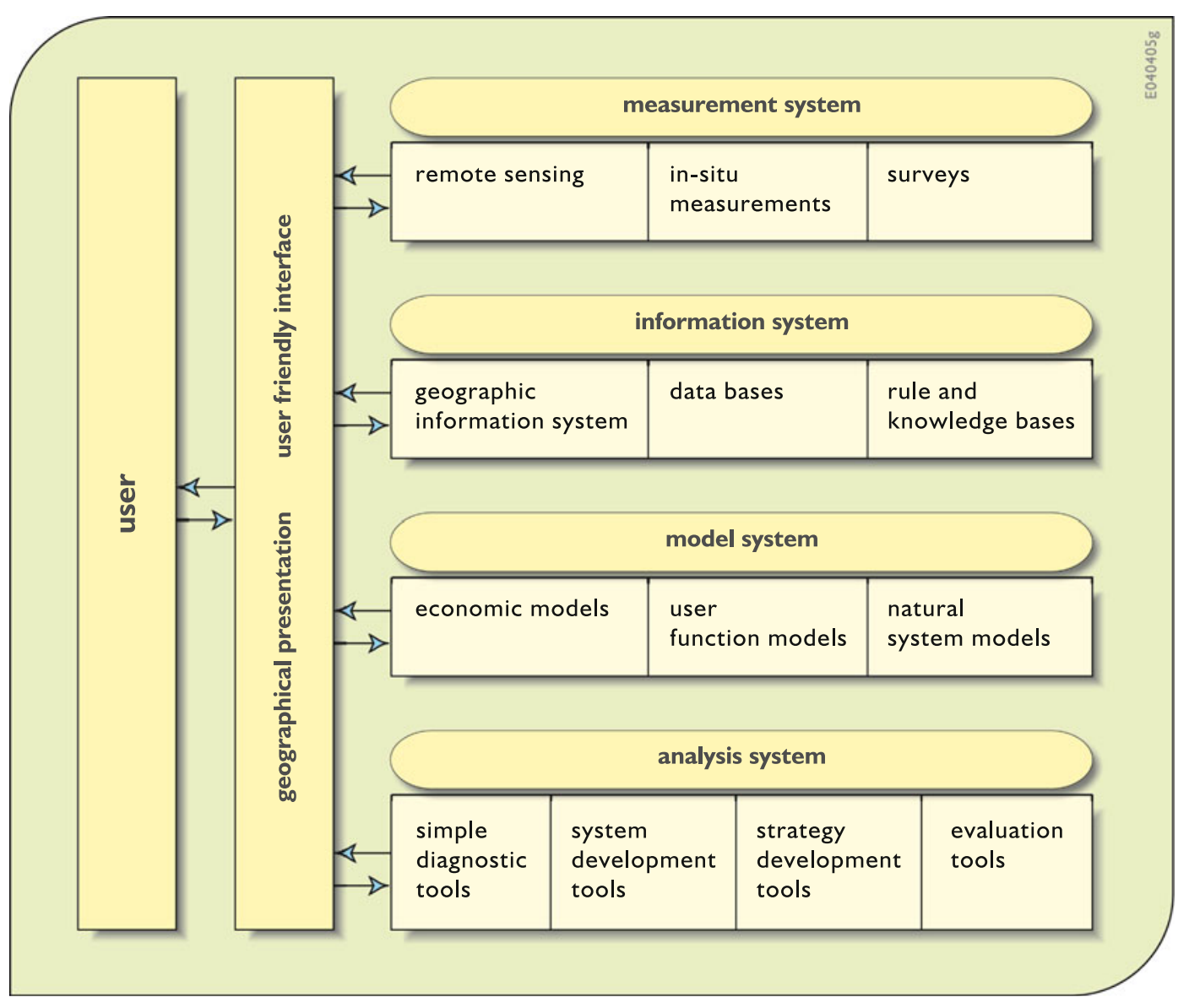

Fig. 2.6 Common components of many decision support systems

systems (Hamlet et al. 1996a, b, c; Palmer et al. 1995; Werick et al. 1996). Each of these model-building 'shared-vision' exercises included numerous stakeholders together with experts in the use of the software. Bill Werick of the Corps writes:

Because experts and stakeholders can build these models together, including elements that interest each group, they become a trusted, consensus view of how the water system works as a whole, and how it affects stakeholders and the environment. Without adding new bureaucracies or reassigning decision making authority, the shared vision model and the act of developing it create a connectedness among problems solvers that resembles the natural integration of the conditions they study.
Now the question is how to get all the stakeholders, many who may not really want to work together, involved in a model-building exercise. This is our challenge! One step in that direction is the development of improved technologies that will facilitate model development and use by stakeholders having various backgrounds and interests. We need better tools for building DSSs, not just better DSSs themselves. We need to develop better modeling environments that people can use to make their own models. Researchers need to be building the model-building blocks, as opposed to the models themselves. Researchers need to focus our attention on improving those building blocks that 
can be used by others to build their own models. Clearly if stakeholders are going to be involved in model-building exercises, it will have to be an activity that is enjoyable and require minimal training and programming skills.

Traditional modeling experiences seem to suggest that there are five steps in the modeling process. First, the information the model is to provide is identified. This includes measures of system performance that are of interest to stakeholders. These system performance measures are defined as functions of the behavior or state of the system being modeled. Next this behavior needs to be modeled so the state of the system associated with any 'external' inputs can be predicted. This requires modeling the physical, chemical, biological, economic, ecological, and social processes that take place, as applicable, in the represented system. Third, these two parts are put together along with a means of entering the 'external' inputs and obtaining in meaningful ways the outputs. Next the model must be calibrated and verified or validated, to the extent it can. Only now can the model be used to produce the information desired.

This traditional modeling process is clearly not going to work for those who are not especially trained or experienced or even interested in these modeling activities. They need a model-building environment where they can easily create models that

- they understand,

- are compatible with available data,

- work and provide the level and amount of information needed,

- are easily calibrated and verified when possible, and

- give them the interactive control over data input, editing, model operation and output display that they can understand and need in order to make informed decisions.

The challenge in creating such model-building environments is in making them sufficiently useful and attractive so that multiple stakeholders will want to use them. They will have to be understandable. They will have to be relatively easy and transparent, and even fun, to build. They must be capable of simulating and producing different levels of detail with regard to natural, engineering, economic, and ecological processes that take place at different spatial and temporal scales. And they must require no programming and debugging by the users. Just how can this be done?

One approach is to develop interactive modeling 'shells' specifically suited to modeling environmental problems. Modeling 'shells' are data-driven programs that become models once sufficient data have been entered into them.

There are a number of such generic modeling shells for simulating water resource systems. AQUATOOL, RIBASIM, MIKE-BASIN and WEAP are representative of interactive riveraquifer simulation shells that require the system to be represented by, and drawn in as, a network of nodes and links (e.g., Fig 2.7 from WEAP). Each node and link require data, and these data depend on what that node and link represent, as well as what the user wants to get from the output. If what is of interest is the time series of quantities of water flowing, or stored, within the system resulting from reservoir operation and/or water allocation policies, then water quality data need not be entered, even though there is the capability of modeling water quality. If water quality outputs are desired, then the user can choose the desired various water quality constituents. Obviously, the more types of information desired or the greater spatial or temporal resolution desired, in the model output, the more input data required.

Interactive shells provide an interactive and adaptive way to define models and their input data. Once a model is defined, the shell provides the interface for input data entry and editing, model operation, and output data display.

To effectively use such shells, some training is useful. This training pertains to the use of the shell and what it can and cannot do. The developers of such shells have removed the need to worry about data base management, solving systems of equations, developing an interactive interface, preserving mass balances and 


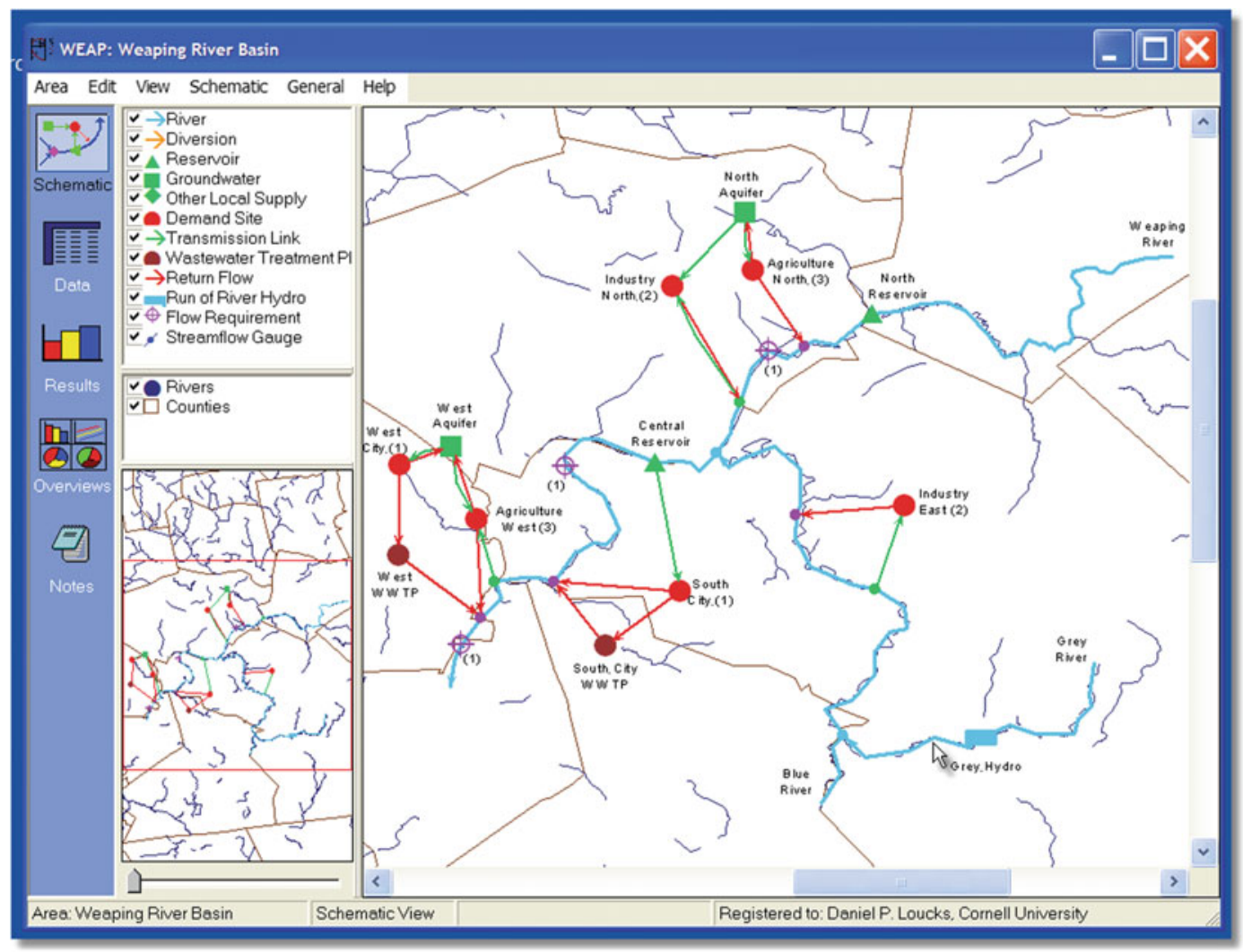

Fig. 2.7 The main interface of the WEAP program, which is typical of a variety of generic river basin models that are able to simulate any river system drawn into the computer using a node-link network

continuity of flow, and the like. Any assumptions built into the shell should be readily transparent and acceptable by all before its use in any shared vision exercises.

\subsubsection{Open Modeling Systems}

The next step in shared-vision modeling will be to create a modeling environment that will enable all stakeholders to include their own models in the overall system description. Stakeholders tend to believe their own models more than those provided by governmental agencies or research institutes. Their own models include the data they trust, and are based on their own assumptions and views on how the system works. For example, in transboundary water resources issues, different countries may want to include their own hydrodynamic models for the river reaches in their country.

Various developments on open modeling systems are taking place in Europe and the United States, although most of them are still in a research phase. The implementation of the Water Framework Directive in Europe has stimulated the development of OpenMI (European Open Modelling Interface and Environment). OpenMI will simplify the linking of water-related models that will be used in the strategic planning required by the Water Framework Directive (Gijsbers et al. 2002). An initiative in the United States aims to establish a similar framework for Environmental Models (Whelan and Nicholson 2002). 


\subsection{Conclusions}

In our opinion the most important aspect of model use today is communication. Unless water resource planners and managers can articulate well their needs for information, it will be difficult for modelers to generate such information. If the modelers cannot communicate effectively their modeling assumptions and results, or how others can use their tools to obtain their own results, little understanding will be gained from such models. Both users and producers of modeling analyses must work together to improve communication. This takes time, patience, and the willingness to understand what each has to say and what is really meant by what is said.

To expect everyone to communicate effectively and to fully understand one another may be asking too much. As written in the Bible (Genesis; Chapter 11, Verses 1-9) there was a time when everyone on the earth was together and spoke one language. It seems these people decided to build a tower "whose top may reach into the heaven." Apparently this activity got the attention of the Lord, who for some reason did not like this tower building idea. So, according to the Bible, the Lord came down to earth and "confounded the peoples language so they could not understand one another." They could no longer work together to build their tower.

Is it any wonder we have to work hard to communicate more effectively with one another, even in our single, but multidisciplinary, field of water resources planning and management? Let all of us modelers or analysts, planners, and managers work together to build a new tower of understanding. To do this we need to control our jargon and take the time to listen, communicate, and learn from each other and from all of our experiences. Who knows, if we are successful, we may even have another visit from the Lord.

Those who are involved in the development of water resource systems modeling methodology know that the use of these models cannot guarantee development of optimal plans for water resources development and management. Given the competing and changing objectives and priorities of different interest groups, the concept of an "optimal plan" is not very helpful or realistic. What modelers can do, however, is to define and evaluate, in different levels of detail, numerous alternatives that represent various possible compromises among conflicting groups, values, and management objectives. A rigorous and objective analysis should help to identify the possible tradeoffs among quantifiable objectives so that further debate and analysis can be more informed. The art of modeling is to identify those issues and concerns that are important and significant and to structure the analysis to shed light on these issues.

Although water resources planning and management processes are not restricted to mathematical modeling, such modeling is an important part of those processes. Models can represent in a fairly structured and ordered manner the important interdependencies and interactions among the various control structures and users of a water resource system. Models permit an evaluation of the economic and physical consequences of alternative engineering structures, of various operating and allocating policies, and of different assumptions regarding future supplies, demands, technology, costs, and social and legal requirements. Although models cannot define the best objectives or set of assumptions, they can help identify the decisions that best meet any particular objective and assumptions.

We should not expect, therefore, to have the precise results of any quantitative systems study accepted and implemented. A measure of the success of any systems study resides in the answer to the following questions: Did the study have a beneficial impact in the planning and decision-making process? Did the results of such studies lead to a more informed debate over the proper choice of alternatives? Did it introduce competitive alternatives that otherwise would not have been considered?

There seems to be no end of challenging water resource systems planning problems facing water resources planners and managers. How one models any specific water resource problem depends on (a) the objectives of the analysis; 
(b) the data required to evaluate the projects; (c) the time, data, money, and computational facilities available for the analysis; and (d) the modeler's knowledge and skill. Model development is an art, requiring judgment in abstracting from the real world the components that are important to the decision to be made and that can be illuminated by quantitative methods, and judgment in expressing those components and their interrelationships mathematically in the form of a model. This art is to be introduced in Chap. 3.

\section{References}

Ahearne, J. F. (1988). Addressing public concerns in science. Physics Today, 41(9), 36-42.

Austin, T. A. (1986). Utilization of models in water resources. Water Resources Bulletin, 22(1), 49-56.

Borsuk, M. E., Stow, C. A., Higdon, D., \& Reckhow, K. H. (2001). A Bayesian hierarchical model to predict benthic oxygen demand from organic matter loading in estuaries and coastal zones. Ecological Modelling, 143, 165-181.

Brown, C. M., Lund, J. R., Cai, X., Reed, P. M., Zagona, E. A., Ostfeld, A., et al. (2015, August). The future of water resources systems analysis: Toward a scientific framework for sustainable water management. Water Resources Research, 51(8), 6110-6124.

Cai, X., Vogel, R., \& Ranjithan, R., (Eds.). (2013, September/October). Role of systems analysis in watershed management. Journal of Water Resources Planning and Management, 139(5), 461-592.

Carey, W. D. (1988). Scientists and sandboxes: Regions of the mind. American Scientist, 76, 143-145.

Castelletti, A. \& Soncini-Sessa, R. (2007). Topics on system analysis and integrated water resources management. Amsterdam: Elsevier Ltd. ISBN: 978-0-08044967-8.

Fedra, K. (1992). Advanced computer applications. Options, December.

Gass, S. I. (1990). Model world: 1-lave model, will travel. Interfaces, 20(2), 67-71.

Georgakakos, A. P., \& Martin, Q. W. (Eds.). (1996, March). An international review of decision support systems in river basin operation. In Proceedings of the Fifth Water Resources Operations Management Workshop. Arlington, VA.: ASCE.

Gijsbers, P. J. A., Moore, R. V., \& Tindall, C. I. (2002). Hamonil T: Towards OMI, an open modelling interface and environment to harmonise European developments in water related simulation software. The Netherlands, Delft: Delft Hydraulics (internal paper).
Goeller B. (1988). A framework for evaluating success in systems analysis. In H. J. Miser \& E. S. Quade (Eds.), Handbook of systems analysis, craft issues and procedural choices. Chichester: Wiley.

Hamlet, A., et al. (1996a). Simulating basinwide alternatives using the ACT-ACF shared vision models. Mobile District, Mobile, Al.: USACE.

Hamlet, A., et al. (1996b). A history of shared vision modeling in the ACT-ACF comprehensive study. Mobile District, Mobile, Al.: USACE.

Hamlet, A., et al. (1996c). Basic Stella II users manual for the ACT-ACF shared vision models. Mobile District, Mobile, Al.: USACE.

Kindler, J. (1987). Systems analysis approach to water resources management: State of the art. In Symposium on Recent Developments and Perspectives in Systems Analysis in Water Resources Management. Perugia, Italy: WARREDOC.

Kindler, J. (1988). Systems analysis and water resources planning. In Fourth IFAC International Symposium on Systems Analysis Applied to Management of Water Resources. Rabat, Morocco: IFAC. October 11-13.

Loucks, D. P., \& da Costa, J. R. (Eds.). (1991). Decision support systems. NATO Series G. (Vol. 26). Berlin: Springer.

Loucks, D. P., Stedinger, J. R., \& Shamir, U. (1985). Modelling water resources systems: Issues and experiences. Civil Engineering Systems, 2, 223-31.

Maas, A., Hufschmidt, M. A., Dorfman, R., Thomas, H. A., Jr., Marglin, S. A., \& Fair, G. M. (1962). Design of water-resource systems: New techniques for relating economic objectives, engineering analysis, and governmental planning. Cambridge, Mass: Harvard University Press.

Majoni, H., \& Quade, E. S. (1980). Pitfalls of analysis. New York: Wiley.

Miser, H. J. (1980). Operations research and systems analysis. Science, 209, 174-182.

Palmer, R. N., Keys, A. M., \& Fisher, S. (1995). Empowering stakeholders through simulation in water resources planning. In Proceedings of the 20th Conference on Water Resources Planning and Management Division. New York: ASCE.

Pool, R. (1990). Struggling to do science for society. Science, 248, 672-673.

Reynolds, P. J. (1987). Future research needs in systems analysis and to application to water resources management. In International Symposium on Recent Developments and Perspectives in Systems Analysis in Water Resources Management. Perugia, Italy: WARREDOC.

Rogers, P. P., \& Fiering, M. B. (1986). Use of systems analysis in water management. Water Resources Research, 22(9), 146S-158S.

Russell, C. S., \& Baumann, D. D. (Eds.). (2009). The evolution of water resource planning and decision making. Northampton, MA, USA: Edward Elgar.

Shapiro, H. T. (1990). The willingness to risk failure. Science, 250(4981), 609. 
Simon, H. A. (1998). Prediction and prescription in system modelling. In 15th Anniversary of IIASA, International Institute for Applied Systems Analysis. Laxenburg, Austria: IIASA.

Stokey, E., \& Zeckhauser, R. (1977). A primer for policy analysis. New York, W.W: Norton.

Thissen, W. A. H., \& Walker, W. E. (Eds.). (2013). Public policy analysis: New developments (286 pp). New York, Heidelberg, Dordrecht, London: Springer. doi:10.1007/978-1-4614-4602-6

(ISBN

978-1-4614-4601-9; ISBN 978-1-4614-4602-6 (eBook)).

Tomlison, R. (1980). Doing something about the future. Journal of the Operational Research Society, 31, 467476.

Walker, W. E. (1987). Important hard problems in public policy analysis (Report P-7282). Santa Monica, California: Rand Corporation.

Watkins, D. W. Jr., (Ed.). (2013). Water resources systems analysis through case studies: Data and models for decision making (168 pp). Reston, VA: ASCE Press.

Werick, W. J., Whipple, W. Jr., \& Lund, J. (1996). ACTACF basinwide study. Mobile District, Mobile, Al.: USACE.

Whelan, G., \& Nicholson, T. J. (Eds.). (2002). Proceedings of the Environmental Software Systems Compability and Linkage Workshop (NRC report NUREG/CP-0177). March 7-9, 2000. Richland and Washington.: Pacific Northwest National Laboratory. wrm_ch02.qxd 8/31/2005 Page 56.

\section{Additional References (Further Reading)}

Andreu, J., Capilla, J., \& Sanchis, E. (1991). Aquatool. A computer assisted support system for water resources research management including conjunctive use. In D. P. Loucks \& J. R. da Costa (Eds.), Decision support systems (pp. 333-355). Berlin: Springer.

Danish Hydraulic Institute (DHI). (1997). Mikebasin: Operating manual and description. Hørsholm: Denmark.

Delft Hydraulics. (2004). RIBASIM River basin simulation program operating manual and description. The Netherlands, Delft.

Loucks, D. P. (1995, August). Developing and implementing decision support systems: A critique and a challenge. Water Resources Bulletin, Journal of American Water Resources Association. 31(4), 571-82.

O'Callaghan, J. R. (Ed.). (1996). The interaction of economic, ecology and hydrology. London: Chapman $\&$ Hall.
Raskin, P., Sieber, J. \& Huber-Lee, A. (2001). Water evaluation and planning system: User guide for WEAP21. Boston, Mass: Tellus Institute.

\section{Exercises}

2.1 What is a system?

2.2 What is systems analysis?

2.3 What is a mathematical model?

2.4 Why develop and use models?

2.5 What is a decision support system?

2.6 What is shared vision modeling and planning?

2.7 What characteristics of water resources planning or management problems make them suitable for analysis using quantitative systems analysis techniques?

2.8 Identify some specific water resource systems planning problems and for each problem specify in words possible objectives, the unknown decision variables whose values need to be determined, and the constraints or that must be met by any solution of the problem.

2.9 From a review of the recent issues of various journals pertaining to water resources and the appropriate areas of engineering, economics, planning, and operations research, identify those journals that contain articles on water resources systems planning and analysis, and the topics or problems currently being discussed.

2.10 Many water resource systems planning problems involve considerations that are very difficult if not impossible to quantify, and hence they cannot easily be incorporated into any mathematical model for defining and evaluating various alternative solutions. Briefly discuss what value these admittedly incomplete quantitative models may have in the planning process when nonquantifiable aspects are also important. Can you identify some planning problems that have such intangible objectives? 
2.11 Define integrated water management and what that entails as distinct from just water management.

2.12 Water resource systems serve many purposes and can satisfy many objectives. What is the difference between purposes and objectives?

2.13 How would you characterize the steps of a planning process aimed at solving a particular problem?

Open Access This chapter is distributed under the terms of the Creative Commons Attribution-NonCommercial 4.0 International License (http://creativecommons.org/ licenses/by-nc/4.0/), which permits any noncommercial use, duplication, adaptation, distribution and reproduction in any medium or format, as long as you give appropriate credit to the original author(s) and the source, provide a link to the Creative Commons license and indicate if changes were made.
2.14 Suppose you live in an area where the only source of water (at a reasonable cost) is from an aquifer that receives no recharge. Briefly discuss how you might develop a plan for its use over time.
The images or other third party material in this chapter are included in the work's Creative Commons license, unless indicated otherwise in the credit line; if such material is not included in the work's Creative Commons license and the respective action is not permitted by statutory regulation, users will need to obtain permission from the license holder to duplicate, adapt or reproduce the material. 